\title{
Sheathless transcatheter self-expanding aortic valve implantation: An alternative approach to reduce vascular complications
}

\author{
Guido Gelpi, MD, Claudia Romagnoni, MD, Paolo Danna, MD, and Carlo Antona, MD, Milano, Italy
}

Transcatheter aortic valve implantation (TAVI) is a wellrecognized therapeutic option for high-risk patients with aortic stenosis. Its application is booming, and new devices will soon increase the chance to treat more patients. Despite encouragingly good results, vascular complications remain the Achilles' heel of this procedure. According to Valve Academic Research Consortium (VARC) criteria, major vascular complications vary between $10.7 \%$ and $15.3 \%$ in predicting 30-day mortality. ${ }^{1,2}$ The rate of vascular complications has been diminishing thanks to the downsizing of the introducer from $24 \mathrm{~F}$ to $18 \mathrm{~F}$ and the choice of alternative vascular access besides the transfemoral (subclavian, transaortic, and transapical).

\section{CLINICAL EXPERIENCE}

Among 51 patients treated with TAVI between July 2009 and August 2012, 7, with vascular access less than $6 \mathrm{~mm}$, were deemed not suitable for the transapical or transaortic approach. The Heart Team opted to implant the Medtronic CoreValve (Medtronic, Minneapolis, Minn) through the femoral or subclavian artery without the introducer (sheathless). Device success was $100 \%$, and no vascular complication occurred. According to VARC criteria, before and after procedural data are reported in Table 1.

\section{SURGICAL TECHNIQUE}

With local anesthesia and minimal sedation, we perform a surgical incision of $4 \mathrm{~cm}$ for femoral and $6 \mathrm{~cm}$ for subclavian access; the artery is secured with two tourniquets proximally and distally, and two 5-0 prolene-pledgeted purse strings are placed around the incision site for hemostasis. A $6 \mathrm{~F}$ sheath is inserted for guide positioning, then replaced with a $12 \mathrm{~F}$ for balloon valvuloplasty; finally, after removing the $12 \mathrm{~F}$ sheath, the CoreValve System is gently inserted directly into the artery on a stiff wire. A further small extension of the

From the Cardiovascular Surgery Department, "Luigi Sacco" University General Hospital, Milano, Italy.

Disclosures: Authors have nothing to disclose with regard to commercial support.

Received for publication Jan 19, 2013; revisions received March 4, 2013; accepted for publication March 14, 2013; available ahead of print April 8, 2013.

Address for reprints: Guido Gelpi, MD, Cardiovascular Surgery Department, "Luigi Sacco" University General Hospital, Via G. Grassi 74, 20157 Milan, Italy (E-mail: gelpi.guido@hsacco.it).

J Thorac Cardiovasc Surg 2013;146:240-2

0022-5223/\$36.00

Copyright (c) 2013 by The American Association for Thoracic Surgery

http://dx.doi.org/10.1016/j.jtcvs.2013.03.011
TABLE 1. Before and after procedural data

\begin{tabular}{|c|c|}
\hline Data & Value \\
\hline \multicolumn{2}{|l|}{ Baseline characteristics } \\
\hline Age, y & $84 \pm 5$ \\
\hline NYHA III-IV & $2(28.57)$ \\
\hline Diabetes mellitus & $4(57.14)$ \\
\hline Coronary artery disease & $2(28.57)$ \\
\hline COPD & $3(42.86)$ \\
\hline Renal dysfunction & $2(28.57)$ \\
\hline Logistic EuroSCORE, \% & $22 \pm 9$ \\
\hline Left ventricle ejection fraction, $\%$ & $44 \pm 8$ \\
\hline Previous cardiac intervention & $4(57.14)$ \\
\hline Previous endovascular procedure & $2(28.57)$ \\
\hline Porcelain aorta & $2(28.57)$ \\
\hline \multicolumn{2}{|l|}{ Procedural outcome } \\
\hline Successful valvuloplasty & $7(100)$ \\
\hline Emergent cardiac surgery & $0(0)$ \\
\hline \multicolumn{2}{|l|}{ Postprocedural aortic regurgitation } \\
\hline Mild & $3(42.87)$ \\
\hline Moderate & $1(14.29)$ \\
\hline Severe & $0(0)$ \\
\hline Postprocedural gradient, mmHg & $9 \pm 3$ \\
\hline \multicolumn{2}{|c|}{ Safety end points at $30 \mathrm{~d}$ follow-up according to VARC definition } \\
\hline Overall death & $0(0)$ \\
\hline Stroke & $0(0)$ \\
\hline Major bleeding & $0(0)$ \\
\hline Major vascular complications & $0(0)$ \\
\hline Minor vascular complications & $0(0)$ \\
\hline PM implantation & $1(14.29)$ \\
\hline \multicolumn{2}{|c|}{$\begin{array}{l}\text { Values are given as mean } \pm \text { SD or number (percentage). } N Y H A \text {, New York He } \\
\text { Association; } C O P D \text {, chronic obstructive pulmonary disease; VARC, Valve Academ } \\
\text { Research Consortium; } P M \text {, pacemaker; EuroSCORE, European System for Cardi } \\
\text { Operative Risk Evaluation. }\end{array}$} \\
\hline
\end{tabular}

artery incision avoids any vessel damage. If postdilatation is required, the system is retrieved and the $12 \mathrm{~F}$ is repositioned, securing hemostasis with the purse string. The artery is closed directly at the end of the procedure.

\section{DISCUSSION}

As cardiovascular surgeons, we are used to the "sheathless technique" because of practice with sheathless endovascular prosthesis (ie, Endurant; Medtronic). Accutrack (Medtronic) is the CoreValve delivery system that allows navigating and delivering the valve in the correct position. All 4 different sizes of the CoreValve are mounted into the $18 \mathrm{~F}$ Accutrack that protects and keeps the valve crimped, with a smooth plastic cover. The maximum outer diameter of the Accutrack is $18 \mathrm{~F}(6 \mathrm{~mm})$ for the first $7 \mathrm{~cm}$, 


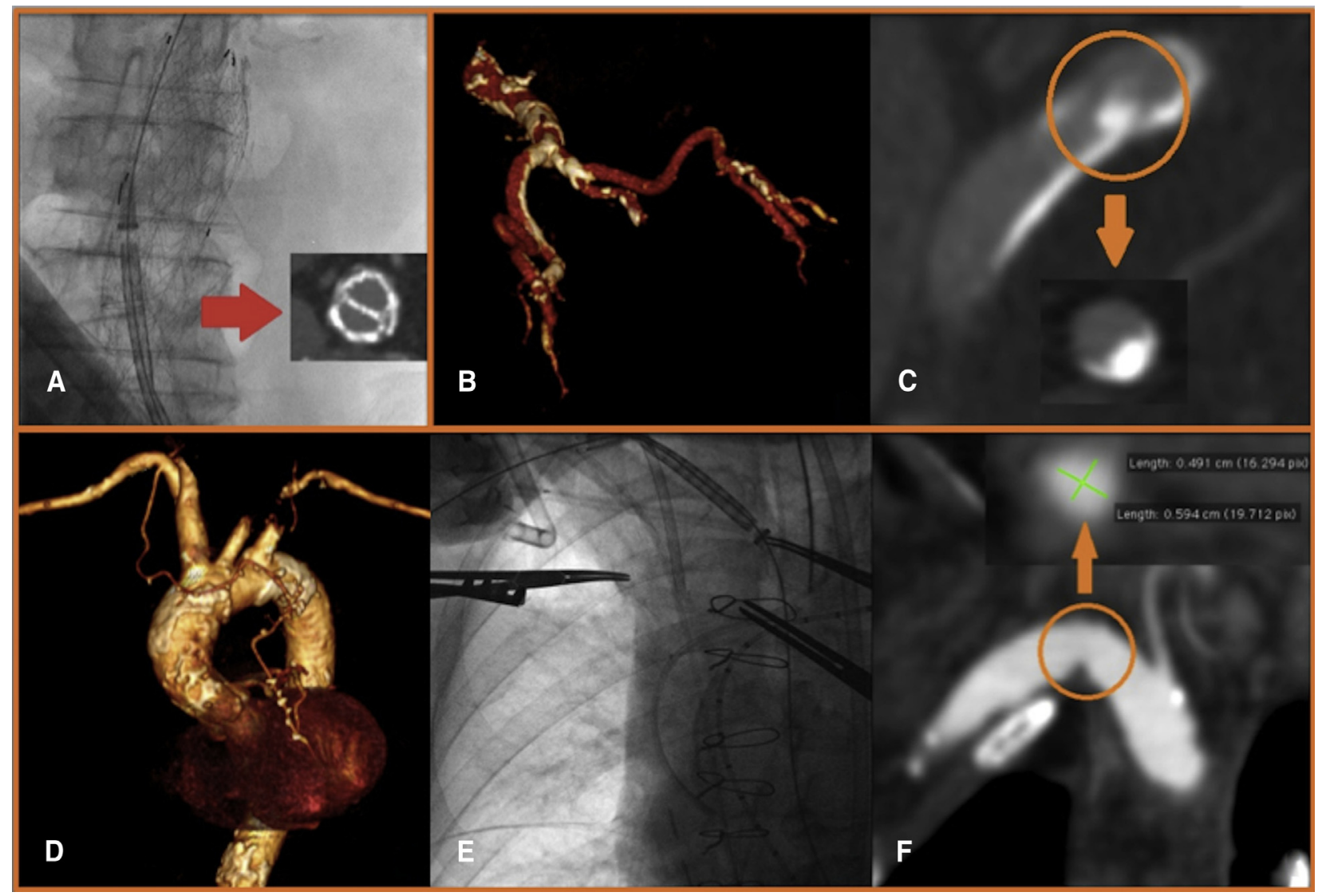

FIGURE 1. Sheathless femoral transcatheter aortic valve implantation (TAVI) in a patient with aortoiliac endoprosthesis (A) and in a patient with severe calcifications of aortic carrefour (B and C); sheathless right subclavian TAVI in a patient with previous coronary artery bypass grafting, porcelain aorta, diseased femoral and iliac access, occluded left subclavian artery, and small right subclavian artery (D-F). Arrows indicate the axial computed tomography scan details. The computed tomography scan vessel diameters are in green.

$12 \mathrm{~F}$ for the middle $14.6 \mathrm{~cm}$, and $15 \mathrm{~F}$ for the last $90.7 \mathrm{~cm}$, whereas the outer diameter of a compatible $18 \mathrm{~F}$ introducer is $7.2 \mathrm{~mm}$. The difference between a sheath and sheathless procedure is only $1.2 \mathrm{~mm}$, but it means a reduction in access vessel diameter of $16.7 \%$. This technique allows us to avoid keeping a stiff $30-\mathrm{cm}$ length introducer in the access vessel for the entire procedure. The 6-mm delivery system passes through the vascular access for a few seconds and, for just $7 \mathrm{~cm}$, reducing the risk of artery recoil or dissection. The smoother Accutrack's nose follows curvature or indentation of the artery better than the rigid introducer's dilatators. Moreover, avoiding introducer obstruction, subclavian sheathless access allows a greater flow to the internal thoracic artery (ITA) also in case of patent ITA to the left anterior descending artery. ${ }^{3}$ Indeed, thanks to the flexibility of the delivery system, it becomes possible to perform a TAVI procedure even in case of important vessel tortuosity or in case of previous aortic stent or endovascular prosthesis implantation (Figure 1). As reported by Hayashida et al, ${ }^{4}$ a sheath to femoral artery ratio (SFAR) of 1.05 predicted a statistically significantly higher rate of VARC major complications and 30-day mortality. The authors identified, for an $18 \mathrm{~F}$ introducer, a minimal noncalcified ileofemoral artery access of $6.5 \mathrm{~mm}$ and of $7.2 \mathrm{~mm}$ for calcified artery access. A sheathless procedure allows 6-mm artery access.

The main drawback of this off-label approach is the impossibility to recapture the CoreValve. However, also using the introducer, this procedure may be difficult and risky (particularly for the subclavian access). ${ }^{5}$ To minimize the risk of suboptimal positioning or device displacement during a sheathless procedure, we always deploy the CoreValve under rapid pacing. With the advent of new device generation, with a smaller diameter, a sheathless technique will remain a valid option, particularly in cases of small and diseased vessels.

\section{CONCLUSIONS}

Patients with major vascular complications had a 2-fold increase in mortality, and vascular complications are strictly related to SFAR. ${ }^{4}$ The sheathless technique, allowing a smaller $16.7 \%$ artery diameter, is an alternative to standard access. The "Heart Team" should consider this off-label option when conventional access is precluded 
and to avoid intricately more invasive access, such as transaortic and transapical, that requires general anesthesia.

\section{References}

1. Generous P, Webb JG, Svensson LG, Kodali SK, Satler LF, Fearon WF, et al. Vascular complications after transcatheter aortic valve replacement: insights from the PARTNER (Placement of AoRTic TraNscathetER Valve) trial. $J \mathrm{Am}$ Coll Cardiol. 2012;60(12):1043-52.

2. Leon MB, Piazza N, Nikolsky E, Blackstone EH, Cutlip DE, Kappetein AP, et al. Standardized endpoint definitions for transcatheter aortic valve implantation clinical trials: a consensus report from the Valve Academic Research Consortium. Eur Heart J. 2011;32:205-17.

3. Bruschi G, Fratto P, De Marco F, Oreglia J, Colombo P, Botta L, et al. The transsubclavian retrograde approach for transcatheter aortic valve replacement: single-center experience. J Thorac Cardiovasc Surg. 2010;140(4):911-5.

4. Hayashida K, Lefèvre T, Chevalier B, Hovasse T, Romano M, Garot P, et al. Transfemoral aortic valve implantation new criteria to predict vascular complications. JACC Cardiovasc Interv. 2011;4(8):851-8.

5. Testa L, Brambilla N, Laudisa ML, De Carlo M, Lanotte S, Latini RA, et al. Right subclavian approach as a feasible alternative for transcatheter aortic valve implantation with the CoreValve ReValving System. EuroIntervention. 2012;8:685-90. 